\title{
DRUG FACTS, VALUES, AND THE MORNING-AFTER PILL
}

\author{
Christopher ChoGlueck
}

\begin{abstract}
While the Value-Free Ideal of science has suffered compelling criticism, some advocates like Gregor Betz continue to argue that science policy advisors should avoid value judgments by hedging their hypotheses. This approach depends on a mistaken understanding of the relations between facts and values in regulatory science. My case study involves the morningafter pill Plan B and the "Drug Fact" that it "may" prevent implantation. I analyze the operative values, which I call zygote-centrism, responsible for this hedged drug label. Then, I explain my twofold account of valueladenness, involving the constitutive role of value judgments in science and the social function of facts as political tools. Because this drug fact is ineliminably value-laden in both senses, I conclude that hedged hypotheses are not necessarily value-free.
\end{abstract}

\section{Uncertain Yet Powerful KnOWLedge}

In 2014, the US Supreme Court issued a landmark decision in Burwell v. Hobby Lobby involving contraceptive coverage and religious freedom. The main scientific premise of this case was a "Drug Fact" from the Food and Drug Administration (FDA) that morning-after pills like the well-known drug Plan B "may also prevent fertilization of a release egg (joining of sperm and egg) or attachment of fertilized egg to the uterus (implantation)" along with ovulation (Fig. 1; emphasis added). ${ }^{1}$ Yet, around the same time, the French manufacturer removed a similar statement about the off chance of preventing implantation from its patient package inserts, in part because of pressure from the International Federation of Gynecology and Obstetrics. ${ }^{2}$ Why has this "drug fact" about emergency contraception attracted so much public controversy?

Philosophers of science provide some guidance here to understand this situation, particularly the value-ladenness of this scientific claim, that is, the different 


\begin{tabular}{|c|c|}
\hline Drug Facts & Drug Facts (continued) \\
\hline 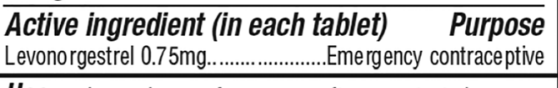 & $\begin{array}{l}\text { ake the second tablet } 12 \text { hours after you take the first tablet } \\
\text { prescription only for age } 17 \text { and under. If age } 17 \text { or under, see } \\
\text { a healthcare professional. }\end{array}$ \\
\hline $\begin{array}{l}\text { Use reduces chance of pregnancy after unprotected sex } \\
\text { (if a contraceptive failed or if you did not use birth control) }\end{array}$ & \multirow{6}{*}{ 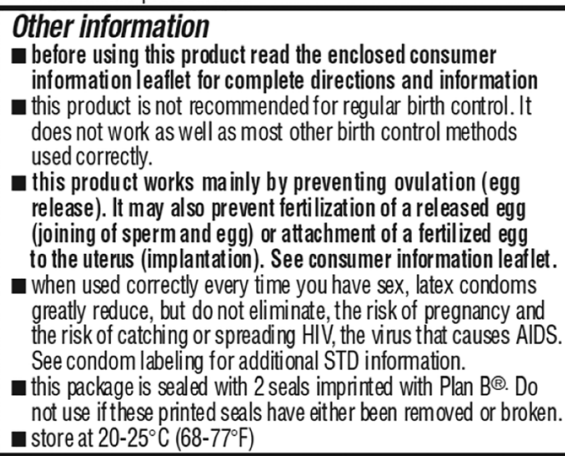 } \\
\hline $\begin{array}{l}\text { Warnings } \\
\text { Allergy a lert: Do not use if you have ever had an allergic } \\
\text { reaction to levonorgestrel }\end{array}$ & \\
\hline $\begin{array}{l}\text { Sexually transmitted diseases (STDs) a lert: This product } \\
\text { does not protect against HIV/AIDS or other STDs }\end{array}$ & \\
\hline $\begin{array}{l}\text { Do not use } \\
\text { Q if you are already pregnant (because it will not work) } \\
\text { q for regular birth control } \\
\end{array}$ & \\
\hline When using this product you may have & \\
\hline 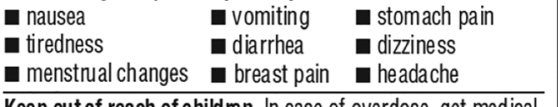 & \\
\hline $\begin{array}{l}\text { Keep out of reach of children. In case of overdose, get medical } \\
\text { help or contact a Poison Control center right away. }\end{array}$ & \multirow{2}{*}{$\begin{array}{l}\text { Inactive ingredients } \\
\text { colloidal silicon dioxide, corn starch, gelatin, lactose } \\
\text { monohyd rate, magnesium stearate, potato starch, talc }\end{array}$} \\
\hline \multirow{2}{*}{$\begin{array}{l}\text { Directions } \\
\square \text { women } 18 \text { years of age and over. } \\
\text { take the first tablet as soon as possible but no later than } \\
72 \text { hours ( } 3 \text { days) after unprotected sex. The sooner you } \\
\text { take the first tablet, the more effective it will be. }\end{array}$} & \\
\hline & $\begin{array}{l}\text { TPQuestions or comments? } \\
\text { For mo re information or to speak to a healthcare professional, } \\
\text { call 1-800-330-1271, } 24 \text { hours a day/7 days a week. } \\
\text { Visit our Web site at www.go2planb.com }\end{array}$ \\
\hline
\end{tabular}

Figure 1. The official "Drug Facts" for Plan B once FDA approved for over-the-counter sale in 2006. Note the mechanism ("口 this products works . ..") listed in boldface after the third bullet under "Other information." This powerful and contested piece of information is saddled by much more mundane facts about ingredients, directions, and storage.

ways that values are "encoded" into background assumptions and standards of evidence. ${ }^{3}$ Scientists make value judgments throughout the process of knowledge production, from forming concepts to reasoning between theories and data. ${ }^{4}$ The values researchers utilize include community standards, social norms, and ethical principles, creating a whole "tapestry of values" with different threads woven together to form scientific knowledge. ${ }^{5}$

Yet some philosophers object that even if science could involve ethical value judgments, ideally, scientists ought to provide "value-free advice" in policy making to separate science from politics. ${ }^{6}$ For instance, Gregor Betz recommends that scientists avoid relying on ethical assumptions about inductive risks by formulating "hedged hypotheses that make the uncertainties explicit." " To communicate "practical certainty" without ethical values, he suggests using epistemic modalities, such as "it is possible [that ...]," which is akin to Plan B's drug label. ${ }^{8}$

In this paper, I show why such allegedly value-free solutions for science advising are not so value-free after all. Focusing on the particular case of the hedged "drug fact" on Plan B's label, I argue that knowledge can be value-laden in two distinct but related senses: a constitutive sense, in which researchers' values play 
a role in managing different uncertainties about a claim's status as fact, and a social sense, in which the claim's uneven social currency differentially enables certain groups to use it as a tool to promote their political goals and interests at the expense of others' goals. By articulating the interdependence of science advisors' value judgments and the power of their scientific claims, this paper demonstrates how this hedged scientific claim was ineliminably and inextinguishably valueladen.

This analysis is significant for philosophers of public policy because it provides a robust and comprehensive account of how and why values pervade scientific advice. While philosophers of science and medicine have begun to analyze science-based or evidence-based policy, there remains the need to analyze values specifically in the policy process. ${ }^{9}$ Additionally, previous philosophical analyses of commercial values in regulatory science pit economic interests against public health concerns. ${ }^{10}$ Thinking more broadly, I consider the entanglement of economic and health interests in medicine and pharmaceutical policy.

This study also has social significance because it challenges the plausibility of science advisors" ability to use "hedged hypotheses" to remain value-free. By exposing how constitutive and social value-ladenness allows for social control, this paper can inform efforts to better identify and diagnose injustices in health policy, particularly how values can be imposed through value-laden facts on women, with oppressive consequences.

I begin with some background on Plan B and the science advisors whose values were responsible for its drug label. This analysis draws on the meeting minutes from the FDA's advisory committees, ${ }^{11}$ as well as pertinent medical literature, such as review articles, bioethics articles, and opinion pieces. I survey the value judgments about Plan B's mechanism at different levels of scientific uncertainty and then compare the social implications of the US government's decision with simultaneous developments in France. To conclude, I discuss the inability of science advisors to avoid value judgments by hedging their hypotheses.

\section{Zygote-Centrism and the Case of Plan B's Drug Label}

One of the most recent controversial drugs at the FDA has been the morning-after pill Plan B (a progestin-only formulation of levonorgestrel). ${ }^{12}$ Morning-after pills are one form of emergency contraception taken by cisgender women (and other people who can get pregnant) after unprotected sexual intercourse, to reduce the chances of pregnancy. ${ }^{13}$ It is commonly used as a prophylactic for unwanted pregnancy after birth control failure, unprotected sex, or rape. In 1999, the FDA approved Plan B for prescription-only sale to women 18 and over. At a later 2003 meeting between two FDA advisory committees, women's health advocates collided with anti-abortionists and social conservatives over a supplemental 
application for switching Plan B from prescription-only to over-the-counter access with no age restriction. These women's health advocates wanted to expand access to this postcoital form of birth control, yet the anti-abortionists who opposed such a late-acting pill did so because they believed that it posed a risk to zygotes, which they consider human persons. Although it is beyond this paper's scope, other critics of the switch also worried that increased access to Plan B might promote adolescent promiscuity and disease transmission—despite disconfirming evidence available at the time..$^{14}$

While advisors overwhelmingly voted for the switch (twenty-three to four), the FDA commissioner delayed approval for over 2 years, resulting in the resignation of the director of the Office of Women's Health, Susan Wood. In her public resignation letter, Wood suggested the reason for delay was ideological rather than "based on scientific and clinical evidence," citing Thomas Henry Huxley: "Science commits suicide when it adopts a creed." ${ }^{15}$ Both proponents and critics of the switch criticized the FDA for being "political" rather than "scientific," lamenting decisions in which "politics trumps science." ${ }^{16}$ Yet this either-scienceor-politics framing is not particularly helpful, as regulatory decisions at the FDA and elsewhere always involve both technical and political considerations. ${ }^{17}$ Nonetheless, according to the US Government Accountability Office, the FDA's decision to deny the switch to over-the-counter was "unusual" because of the top-down nature of the delay and the commissioner's justification (based on concerns about adolescents' cognitive abilities). ${ }^{18}$ Furthermore, the few advisors who opposed the switch, as well as the FDA commissioner, were political appointees of President George W. Bush, whose platform was vehemently opposed to abortion and non-abstinence-based contraception. ${ }^{19}$

While the agency eventually approved the drug for over-the-counter sale, Plan B was the first (and only) drug to feature an age restriction (18+). Its new label featured a "drug fact" on the carton, unprecedented among contraceptive labels, conveying in detail the mechanism and its uncertainty: "This product works mainly by preventing ovulation (egg release). It may also prevent fertilization of a released egg (joining of sperm and egg) or attachment of a fertilized egg to the uterus (implantation)" (see Fig. 1). ${ }^{20}$ Given the controversy around Plan B's approval, what was the role of values and politics in the creation and approval of this unique, powerful drug label? In this section, I present the value set of zygote-centrism, including beliefs, interests, and political strategies, as well as alternative values from various women's health advocates.

\subsection{Zygote-Centrism and Its Critics}

In the United States and elsewhere, there are many laws and regulations that treat pregnant cisgender women as mere "fetal containers" or "maternal environments" for the "precious cargo" within. ${ }^{21}$ For instance, the Surgeon General requires all 
alcohol to be labeled about the risks of fetal alcohol syndrome—despite the lack of evidence of adverse effects for light to moderate drinkers-wrongly suggesting that any maternal drinking is utterly irresponsible..$^{22}$ The specific value behind these sorts of laws and gender norms can be called fetal-centrism: that the health, well-being, and rights of pregnant women are separate from, often opposed to, and relatively less important than those of their developing fetuses and potential children. As we shall see, in debates over the morning-after pill, one form of fetal-centric values has played a decisive role in prompting and producing a drug label about its mechanism. Yet, in this case, the focus was less on the fetus and more on the zygote during the earliest stages of embryonic development around the time of conception: in the 8 weeks before an embryo becomes a fetus, during the period between the fusing of egg and sperm (fertilization) and its implantation into the uterine wall.

Zygote-centrism is the set of values and gender norms that prioritize the health, well-being, and alleged rights of fertilized eggs (zygotes) over those of the cisgender women who carry them. ${ }^{23}$ This view of women's reproductive health is particularly common in the Pro-Life or Right-to-Life movement, which Roman Catholics began in the 1960s in response to states' legalization of abortion. ${ }^{24}$ Accordingly, in the health care system, zygote-centric values have been promulgated primarily by Roman Catholic organizations, such as the Catholic Health Association, the Catholic Medical Association, and the US Conference of Catholic Bishops (USCCB). This specific religious connection is important institutionally: during the time of these debates, the bishops oversaw 12 percent of US hospitals and required their adherence to the values and norms in the Ethical and Religious Directives for Catholic Health Care Services ${ }^{25}$ Compared with their critics, the zygote-centrists in this debate included professors from relatively less prestigious universities; practitioners of family medicine, internal medicine, or pharmacy; and representatives of the Pro-Life movement. ${ }^{26} \mathrm{~A}$ few were present at the FDA meeting as voting consultants and non-voting members of the public.

Despite strong connections to Catholic institutions, zygote-centrism is not simply the Catholic, the Christian, or even the religious view, but rather the "Pro-Life" view. For one, Catholics are a heterogeneous group in their beliefs and practices regarding reproduction - evidenced by the abortion-access advocacy of Catholics for a Free Choice. ${ }^{27}$ In addition, many zygote-centrists are non-Catholics, such as Mormons, Evangelical Protestants, and other secular conservatives.$^{28}$ In fact, at the 2003 FDA meeting, socially progressive Christian and Jewish sects supported increased access to emergency contraception. ${ }^{29}$ Nonetheless, zygote-centrism is historically rooted in Catholic theology, and it remains the dominant, orthodox view among the Roman Catholic Church's hierarchy.

Various women's health advocates have criticized the zygote-centric view of women's reproductive health. Throughout the history of emergency contraception, 
there has been a blurry line between researchers, doctors, feminist activists, and entrepreneurs who all advocated for expanding access to the drug for different reasons. ${ }^{30}$ In addition to professors from relatively more prestigious universities, the individuals who criticized zygote-centrism included practitioners of obstetrics and gynecology and business executives. ${ }^{31}$ Several were present at the FDA meeting as either voting advisors or non-voting pharmaceutical representatives.

While joined in their antagonism toward zygote-centrists (and social conservatives), these various women's health advocates were not a unified camp in terms of their beliefs, interests, or strategies. For instance, some pathologized pregnancy and considered the drug a "cure" to the epidemic of unplanned pregnancies, while others rejected this medicalized model of pregnancy and its implicit devaluation of women and motherhood. ${ }^{32}$ Despite lacking unity, they opposed the zygote-centric view along several dimensions, which ultimately impacted their scientific judgment, as we shall see in section 3. The main sites of conflict were the ontology of when a woman's pregnancy begins and another human life starts, the ethics of preventing and ending pregnancy, and the pragmatics of health care and medical decision making.

\subsection{Ontologies of Reproductive Health}

Zygote-centrists defined "conception" and "abortion" to include earlier stages of embryological development than did their critics. For zygote-centrists, fertilization is the moment at which human life begins and a pregnancy is conceived (hence "conception"); therefore, the termination of pregnancy, that is, "abortion," includes inhibition of development any time after a spermatozoon and ovum fuse ${ }^{33}$ In addition, zygote-centrists have included the zygote and later stages of embryonic development in the category of human persons. ${ }^{34}$ To label this ontology as "medical" - and suggest its value freedom rather than its religious/ ethical grounding - some doctors have appealed to Mosby's Medical, Nursing, \& Allied Health Dictionary for the "orthodox" or "traditional medical definition of pregnancy." 35

For their critics, on the other hand, "conception" was synonymous with implantation, so "pregnancy" begins once an embryo implants into the endometrium. Accordingly, "abortion" would exclude pre-implantation interference, which most obstetricians and gynecologists would define as "pregnancy prevention" rather than "pregnancy termination." ${ }^{36}$ Some women's health advocates criticized these zygote-centric beliefs because they could limit women's legal access to abortion. ${ }^{37}$ While these advocates of emergency contraception did not have a common stance on when human personhood begins, they criticized the ontological categories of zygote-centrists as non-medical by appealing to the standardized terminology from the American College of Obstetrics and Gynecology (ACOG) and the "Common Rule" for human subjects research from the US federal government. ${ }^{38}$ 


\subsection{Ethics of Reproductive Health}

These ontological beliefs dovetailed with ethical values, moral principles, and sexual norms. Zygote-centrists argued that zygotes are human persons who deserve full moral status. Thus any interference after fertilization constitutes abortion, which violates "the first right of all humans-the right to stay alive."39 Zygote-centrists also adhered to the sexual norms that limited morally permissible contraceptive use exclusively to cases of rape treatment and only prior to fertilization. ${ }^{40}$ While generally opposed to contraception, Catholic health care ethics permits this limited use in hospitals for emergencies, codified by USCCB directive \#36:

Compassionate and understanding care should be given to a person who is the victim of sexual assault. Health care providers should cooperate with law enforcement officials and offer the person psychological and spiritual support as well as accurate medical information. A female who has been raped should be able to defend herself against a potential conception from the sexual assault. If, after appropriate testing, there is no evidence that conception has occurred already, she may be treated with medications that would prevent ovulation, sperm capacitation, or fertilization. It is not permissible, however, to initiate or to recommend treatments that have as their purpose or direct effect the removal, destruction, or interference with the implantation of a fertilized ovum. ${ }^{41}$

In contrast, the critics of zygote-centrism generally suggested allowing a greater expression of women's self-determination through pregnancy planning, prevention, and termination. ${ }^{42}$ Some women's health researchers and gynecologists argued that emergency contraception could be a legitimate therapeutic option regardless of when it acts because of the financial, psychological, and medical benefits for users. ${ }^{43}$ While some of them focused on the maternal risks of pregnancy, others emphasized the social benefits, such as how greater access to morning-after pills could be a cure for the "epidemic" of unplanned pregnancy. ${ }^{44}$ Women's Capital Corporation (the original drug sponsor of Plan B) promoted sexual norms of responsible planning by choosing its brand explicitly to send the "right public health message" that "when Plan A fails, you can go to Plan B." 45

\subsection{Pragmatics of Reproductive Health}

Connected to these divergent beliefs are practical differences of actions and actors, including political and economic strategies and models of doctor-patient relations. As anti-abortionists, zygote-centrists sought to protect zygotic life by preventing access to abortifacient drugs and spreading information about their post-fertilization potential with scientific publications. ${ }^{46}$ The USCCB lobbied for legal exemptions from federal requirements to furnish patients and employees with insurance coverage for such drugs; in turn, zygote-centric physicians and pharmacists refused providing or filling prescriptions with post-fertilization potential. ${ }^{47}$ 
While the bishops' rules might seem more accommodating-unlike the complete ban on other uses of hormonal contraceptives-the Directives severely limited women's agency by allowing for treatment only after testing for ovulation and pregnancy. ${ }^{48}$ Thus, recent survivors of rape have been subjected to the clinical-ethical judgment of hospital staff as to whether the threat to zygotic life is sufficiently low to offer treatment.$^{49}$ Furthermore, women are much less likely to be offered or prescribed emergency contraception at Catholic hospitals, ${ }^{50}$ with over 80 percent of Catholic hospitals never providing access. ${ }^{51}$ Despite stressing the importance of informing women of their hospital's restrictions, ${ }^{52}$ zygotecentrists justified the paternalistic displacement of the woman's agency, not only to protect developing embryos from abortion but also to shield the Church from scandal and preserve the institution of (heterosexual) marriage from corruption by the "culture of death." 53

The advocates of emergency contraception criticized zygote-centrists for compromising women's health and reducing their agency over their own bodies, rather than making them the primary decision maker. Before FDA approval, demographer James Trussell and his colleagues promoted emergency contraception through publicly accessible information online, by phone, and elsewhere. ${ }^{54}$ Because requiring a doctor's prescription suggested "special paternalistic scrutiny" of women, feminist health advocates like Francine Coeytaux and Barbara Pillsbury pushed for over-the-counter access without prescription or age restriction, a policy supported by many women's health researchers. ${ }^{55}$

Yet promoting women's rights and access with medication entangled the advocates of emergency contraception with commercial interests, specifically in developing its market. ${ }^{56}$ For instance, reproductive rights advocate Sharon Camp founded the International Consortium for Emergency Contraception (ICEC) to increase access to the drug. Camp then started the socially oriented Women's Capital Corporation (WCC) to distribute more widely in order to reduce prices and increase women's choices. Yet, for large-scale manufacturing, WCC had to rely on the Hungarian multinational pharmaceutical company Gideon Richter. ${ }^{57}$ Furthermore, when Barr Pharmaceuticals subsequently acquired Plan B from WCC, women's health advocates gained wider access to the drug for women but were left with a less socially minded, more market-driven company, which was less concerned with birth control accessibility per se and more with increased profit margins.

Thus zygote-centrists espoused various beliefs, commitments, and strategies that contained a host of normative elements. While their critics were disunified in many ways, they converged to challenge zygote-centrists' ontological views about the beginning of pregnancy and, more importantly, over whether pregnancy entails new moral status. Rather than focusing on women's health and wellbeing, zygote-centrists prioritized the rights of zygotes and the responsibilities of 
pregnant women to protect them. To enforce these gender norms, zygote-centrists promoted knowledge about the abortifacient mechanism, strategized to limit Plan B's access, and lobbied for exemptions to laws that required providing contraceptives. Next, we see how these zygote-centric values enabled specific judgments about scientific evidence and how that reasoning in science-advisory committees resulted in the debated "drug fact."

\section{Managing Uncertainty about the Mechanism}

Focusing now on Plan B's label (see Fig. 1), why did the FDA accept this claim about its mechanism as a "drug fact"? More specifically, why did its scientific advisors assert this claim in this way? ${ }^{58}$ This section discusses the reasons FDA advisors and other experts gave for attributing or withholding fact status to the claim that Plan B may also prevent implantation (along with ovulation). By fact status, I mean the epistemic constitution of any empirical claim that scientists judge to be well-evidenced. Scientists have a particular vernacular of "scientific facts" as observations, evidence, or data; in contrast, non-scientists (including policy makers) widely associate "scientific facts" with relative certainty and value-freedom and thus often afford such claims with acceptance, confidence, and authority. ${ }^{59}$ In my analysis here, "drug facts" are a particularly powerful sort of knowledge claim in the science policy realm riddled with uncertainties and value judgments, and the ascription of fact status to such a claim is a historical event debated and accomplished by human actors. ${ }^{60}$

This section analyzes the process of social reasoning behind FDA science advisors' assignment of fact status to this claim about Plan B. ${ }^{61}$ More specifically, I examine the various ways that scientists and doctors managed uncertainties with value judgments, based on the values in section 2 . I argue that this epistemic dependence of facts on values entails their deep entanglement. Synthesizing previous accounts of values in science, this section connects four distinct ways of handling uncertainties - namely, about the relevance of data, the sufficiency of evidence, the interpretation of results, and the description of a phenomenon-which all involve value judgments but operate at different levels of analysis and decision making. ${ }^{62}$ For instance, Helen Longino's account explains how value-laden background assumptions provide heuristics that determine which observations are relevant evidence for a theoretical claim. ${ }^{63}$ In contrast, Heather Douglas focuses on the more concrete level of inductive risk and the sufficiency of evidence for accepting a hypothesis. ${ }^{64}$ She includes data interpretation and characterization as cases of inductive risk, and Kevin Elliott elaborates how describing phenomena and extrapolating results also involve judgments based on values. ${ }^{65}$

In constituting Plan B's "drug fact," zygote-centric values were responsible for the judgments made at each of these levels. This mode of establishing 
scientific knowledge by deep entanglement, I argue, exemplifies the constitutive sense of value-ladenness. I will analyze this complex epistemic situation by providing a survey of disagreements related to value judgments at different "depths" of uncertainty: (§ 3.1) semantics (or description), (§ 3.2) standards, (§ 3.3) interpretations, and (§3.4) heuristics (or relevance). Moving through these categories, we will see different judgments at each level and the interactions between them.

\subsection{Semantics: What Does the Phrase "Post-fertilization Effect" Mean?}

Just about everyone involved in the regulatory process took the phrases "postfertilization effect" and "preventing implantation" to denote the same thing: the existence of an antagonistic effect from a substance on zygote development within the fallopian tubes or uterine cavity. However, because even describing an effect can involve value judgments, their connotations of these phrases differed ${ }^{66}{ }^{\text {For }}$ zygote-centrists, "preventing implantation" occurred between human persons and, moreover, against a person, connoting abortion and the violation of the "right to life." ${ }^{\prime 67}$ In contrast, many women's health advocates took this antagonistic effect to occur solely within and for one person. For most reproductive health researchers, "preventing implantation" connoted the different benefits for women users, such as improved safety (fewer side effects than systematically suppressing ovulation) and increasing effectiveness (with effects lasting 3 to 6 days after intercourse) ${ }^{68}$ Following zygote-centrists' opposition to these pills, advocates of emergency contraception later came to connote "preventing implantation" with a risk to women because the potential to prevent implantation posed a barrier to wider access. ${ }^{69}$ Accordingly, zygote-centrists shifted the semantics of the debate with their oppositional values.

\subsection{Standards: How Much Evidence for an Anti-implantation Effect Is Enough?}

At the 2003 FDA meeting, physician Joseph Stanford insisted the committee take seriously those post-fertilization effects that occur "at times" or at least "some of the time." ${ }^{70}$ For most FDA advisors, an antagonistic effect of Plan B with implantation seemed either too poorly evidenced or "so speculative" that it was beyond warranting any confident assertion. ${ }^{71}$ Only the few zygote-centrists like Stanford claimed that the evidence weighed in favor of preventing implantation or at least that "there's data on both sides" of the debate. ${ }^{72}$ To understand why, we move beneath the surface level of semantics to the next level of uncertainty involving inductive risks. ${ }^{73}$ Zygote-centrists and their critics prioritized different risks and thus used different standards of evidence. ${ }^{74}$

To minimize the risks to zygotic life, zygote-centrists required relatively less evidence by promoting the standard of biological plausibility for the existence 
of anti-implantation events. In a bioethics review article, pharmacist John Wilks argued that if hormones affected any implantation factor, they would risk zygotes' "rights" because of "the multifactorial nature of embryo implantation." 75 To minimize risking rights violations, Wilks thought that evidencing the biological plausibility of indirect effects on endometria (and the less than 100 percent effectiveness of ovulatory suppression) was sufficient evidence for inferring a post-fertilization effect.

Similarly, Stanford had argued in print, along with his colleagues Chris Kahlenborn and Walter Larimore (both physicians), for a standard of remote possibility involving a very low likelihood threshold. ${ }^{76}$ According to their own statements, these zygote-centrists were interested not only in post-fertilization effects "definitely proven to exist or proven to be a common event" but also "rare but important events ... even if the possibility is judged to be remote." 77 Their ethical justification for this standard was that zygote-centric patients deserve the right to informed consent, and providers, the right to conscience. ${ }^{78}$ They maintained that this standard had been met: emergency contraception pills are insufficient to suppress ovulation every time (as evidenced by indirect hormonal markers); their constitutive chemicals affect the endometrial histology and uterine hormone receptor levels; and during drug trials, both pre- and post-ovulatory treatment reduced pregnancy counts.

Women's health advocates criticized these zygote-centric standards involving biological plausibility, instead requiring a much higher burden of proof because of the risk to patients' access. Biologist Horacio Croxatto and his colleagues argued that effects on endometrial receptivity cited by zygote-centrists were insufficient evidence: markers of receptivity were established in rats but not humans, and such alterations are likely inconsequential "in real life situations." ${ }^{\text {" }} 9$ Without the direct connection of these effects to lower implantation rates in humans, they rejected zygote-centrists' assessments. The available evidence was not weighty enough with such high stakes as women's access and health.

However, not all women's health advocates were as willing as Croxatto to reject outright the possibility of a post-fertilization effect. Realizing that zygotecentrists were interested in the rare and remote sort of possibility, Trussell and his colleagues argued that the research at that time could not provide an empirical test with the level of certainty required to assuage their doubts. ${ }^{80}$ Nonetheless, to them, a post-fertilization effect seemed "speculative, since virtually no evidence supports that [implantation-prevention] mechanism and some evidence contradicts it." 81 Accordingly, they cautioned against allowing the zygote-centric standard and their "politics of doubt" to further impede the access to the drug for women. Neither in-print criticism from Croxatto et al. nor in-person criticism from Trussell et al. made an impact: the drug label was instead based on the zygote-centric standards of mere biological plausibility and rare, remote possibilities. 


\subsection{Interpretations: Does a Given Study Evidence an Anti-implantation Effect?}

The impact of values continued into deeper layers of uncertainty, moving from weighing sets of data into the interpretation of data. ${ }^{82}$ During the FDA meeting, pharmaceutical representative Carole Ben-Maimon concluded that "there really is no data to suggest that there's any impact on implantation or fertilization. ${ }^{.83}$ Yet zygote-centrist Stanford objected to Ben-Maimon, contending that "the most to date compelling piece of data on the side that says this may work after fertilization at times ... is the data that it's effective up to four or five days after." ${ }^{\prime 4} \mathrm{He}$ considered trial data from the World Health Organization (WHO) to be the best evidence for a post-fertilization effect, claiming that the WHO study "suggests that it is working after fertilization some of the time" because the drug was (still) 60 percent effective around 5 days after treatment. ${ }^{85}$

Stanford's claim is based on the WHO's multicenter, randomized trial led by Helena von Hertzen. Pregnancy rates increased after delaying treatment beyond 3 days post-coitus, reducing efficacy from 80 percent to 60 percent. ${ }^{86}$ Yet in their publication, von Hertzen's team interpreted this pattern as a form of negative evidence, against its effectiveness over time: "a trend towards a lower efficacy with longer delay." ${ }^{\text {" T7 }}$ Thus Stanford had re-interpreted the data more positively, as sustained efficacy that confirmed post-fertilization inhibition. His interpretation was immediately challenged by FDA chairwoman Linda Giudice, who argued that the alleged "five-day window can be interpreted" alternatively as the result of very late ovulation and fertilization because sperm can survive in the uterus up to 5 days. ${ }^{88}$

The WHO study, nonetheless, was the primary piece of evidence that zygotecentrists presented at the meeting for a post-fertilization effect. Stanford focused on the enduring horizontal trend of time elapsed and extrapolated a lasting contraceptive capacity. His re-interpretation is likely based on his zygote-centric interest in the remote possibility of implantation prevention because of its risk to any individual zygote's life. Unconcerned with these sorts of risks, von Hertzen and Giudice did not see these data as positive evidence for a secondary mechanism. Instead, they focused on the downward vertical trend of effectiveness and extrapolated the lowered ability of the drug to prevent pregnancy with longer delays. Despite alternative interpretations of the data and unanswered criticism of the re-interpretation, Stanford's zygote-centric judgment stood as "the evidence" supporting this mechanism.

\subsection{Heuristics: What Counts as Evidence for an Anti-implantation Effect?}

Descending into a deeper level of uncertainty, we turn to how values as heuristics provide theoretical guidance for empirical inquiry. ${ }^{89}$ In the Plan B debates between 
advisors, background assumptions guided how individuals demanded and collected more evidence, such as with ectopic pregnancy (implantation outside the uterus). In addition to the risks that ectopic pregnancy poses for women, it also has additional moral salience for zygote-centrists as the tragic loss of human life implanted inviably. Accordingly, Stanford and his colleagues highlighted how observational data on ectopic rates could provide mechanistic insights: if the morning-after pill slows smooth-muscle relaxation in the fallopian tubes or reduces endometrial receptivity, then the rate of extrauterine to intrauterine pregnancies should be higher in women who use these pills..$^{90}$ The only study these zygote-centrists found that measured ectopic pregnancy rates had a small effect size. They found this "supporting the possibility of one or more postfertilization effects," and they demanded a "much larger series of hormonal [emergency contraception] pregnancies" for further confirmation..$^{91}$

Values also influenced judgments about delimiting the category of "evidence." Some women's health advocates criticized zygote-centrists' reliance on these observational data on ectopic pregnancy, instead demanding more experimentally rigorous evidence to minimize risks to patients' access. For instance, Croxatto and his colleagues designed a series of experiments to pinpoint implantation rates directly to meet their higher standards of evidence, rather than relying solely on indirect measures of embryological development already available, such as observational statistics, receptivity markers, and hormone levels (see $\S 3.2$ ). They counted the number of eggs ovulated, fertilized, and implanted with levonorgestrel administration at various times throughout the ovarian cycles of rats, Cebus monkeys, and humans. In each study, they found that post-coital treatment affected only the rate of ovulation, not fertilization or implantation, so they took the debate to be settled, and the threat to access quelled..$^{92}$ This methodologically strong, disconfirming evidence was available at the time of labeling, but it did not make an impact at the FDA, suggesting that the zygote-centrists again set the heuristics that determined what counted as evidence, and what did not, for labeling Plan B.

\subsection{Constituting the "Drug Fact"}

Originally, Barr Pharmaceuticals was planning to include the mechanism only on the less regulated parts of the label, as is common. ${ }^{93}$ However, five members of the advisory committee strongly suggested describing the mechanism "at the point of purchase," so Barr and the FDA eventually decided to include it more officially as a "drug fact" on the carton, which later migrated onto the FDA website. ${ }^{94}$ Its phrasing comes from zygote-centrist Stanford, who suggested avoiding the contested term "abortion" and instead using "something along the lines of Plan B may work to prevent pregnancy by preventing fertilization or preventing implantation" to accommodate "people at different points of understanding." 95 
This way, the label would not simply say that "Plan B does not cause abortion," which would beg the question about the definition of abortion against zygotecentric values.

This hedged language might at first appear to be a compromise between zygote-centrists and their different critics. However, advisors' assertions about the fact status of this claim that "Plan B may also prevent implantation" were based on zygote-centric values, involving the determination of the category of "the evidence," interpretation of that evidence, their standards for weighing it, and the connotations of the phrase under debate. At the time of labeling in 2006, only zygote-centrists affirmed that this claim about Plan B was a well-evidenced "drug fact." While some other advisors were willing to label Plan B with a remote possibility of this anti-implantation effect, they did so only because of zygote-centric women's rights as patients to informed consent and the current untestability of such a rare effect. Nonetheless, even the more sympathetic women's health researchers suggested the need for actively undermining this mechanistic possibility: "Women should also be informed that the best available evidence indicates that Plan B's ability to prevent pregnancy can be fully accounted for by mechanisms that do not involve interference with postfertilization events." ${ }^{96}$

Thus, the zygote-centric view thoroughly constituted this claim's status as a "drug fact" because of how scientists managed uncertainty at various levels with specific value judgments. Yet one might object that even if the influence of zygote-centric values were widespread, we would be able to untangle their messy influence nonetheless. Accordingly, if the value judgments are identifiable, science advisors can atomize and eliminate the values, retaining the possibility of value-freedom in regulatory science.

This objection is misleading because of the holistic influence of values: in addition to the operation of zygote-centric values in managing uncertainty at specific levels, there was also an interaction between the levels. This interactivity transcended levels by reinforcing judgments and rendering their competing evaluations coherent, thus exemplifying how fact and value are deeply entangled. For instance, judgments about standards of evidence (\$ 3.2) influenced interpretations of data (\$ 3.3), such as when Stanford re-interpreted the WHO data as positive evidence for implantation prevention because he was interested in the rare, remote possibility of any aborted zygote. As another example of interactivity, weighing the evidence ( $(3.2)$ influenced categorizing data as "evidence" (§ 3.4), such as the disparagement of Croxatto and his colleagues of the available indirect measures and his lab's later attempts to provide more exacting evidence to protect access. Deep entanglements thwart the possibility of value-freedom because they demonstrate the integrated, holistic nature of the influence of values on judgment.

While the constitutive sense of value-ladenness explains how values enter scientific knowledge, it does not reveal why certain values prevail (over others). To 
answer that question, we now consider the social function of FDA "drug facts" in the political economy of knowledge.

\section{Powerful Knowledge about the Mechanism}

Even if fact and value are deeply entwined, why do specific values come to constitute particular pieces of knowledge like Plan B's drug fact? To understand why values are embedded in knowledge, we turn to the social value of that knowledge as a political and economic tool for accomplishing goals and protecting interests. ${ }^{97}$ Philosophers of science have noted how social context colors and sustains certain values in scientific knowledge claims, such as how biological theories of sex and gender have been used endlessly and successfully to legitimate the exclusion of women from positions of power. ${ }^{98}$ While scientific facts are a useful and reliable form of knowledge, they also have social lives that go beyond their scientific origins. ${ }^{99}$

I argue that, in addition to being constitutively value-laden, Plan B's "drug fact" about implantation was value-laden in an additional sense involving its asymmetrical social function. Like other tools, mechanistic knowledge about emergency contraception has many potentials, such as working either for or against women's agency and access. Yet, as we saw in section 3, anti-abortionist advisors at the FDA created this drug fact to protect zygotes. Since then, it has had the social utility to differentially enable zygote-centrists to attain their political goals at the cost of the interests and well-being of women. This case illustrates how, more generally, knowledge is value-laden in the social sense when its social utility (political/economic function) is unequally limited by its social currency (perceived legitimacy) in the power structures of society. To explain this second sense of value-ladenness, this section contrasts the social function of drug labels for emergency contraception between the United States and France.

Beginning on the west of the Atlantic, the FDA's label was useful for two groups: for one, it afforded zygote-centrists the social currency to refuse providing Plan $B$ against their wishes. Zygote-centrists could now back-up their claims about the abortifacient potential of Plan B with an authoritative label to refuse financing and providing the drug. Zygote-centric practices of provider refusal increased throughout the decade, especially with "conscientious objectors" in pharmacies, despite professional censure. ${ }^{100}$

In addition, it offered the producers of the drug the financial currency to expand their market. ${ }^{101}$ While most women's health advocates preferred no label at allbecause of how this hedged claim was being used to support anti-abortionists' goals - they had succeeded in the switch to non-prescription access. ${ }^{102}$ This switch would expand women's access to the drug and, more crucially for the drug manufacturers, open a profitable over-the-counter market. Between 2002 and 2010, the percentage of women of reproductive age who had used emergency 
contraception increased from 4 percent to 11 percent (2.1 to 5.8 million). ${ }^{103}$ More access meant more returns: Barr Pharmaceuticals' annual sales of Plan B doubled to 80 million USD once approved for over-the-counter sale. ${ }^{104} \mathrm{After}$ Teva acquired Barr's assets in 2008, the sales of Plan B continued to increase. ${ }^{105}$

This limited economic compromise balanced the interests of the producers of Plan B with anti-abortionists' ethical concerns. Unfortunately, the compromise did not promote the interests of those who rely on their zygote-centric employers for insurance coverage of the costly, time-sensitive drug that had doubled in price. ${ }^{106}$ As we shall see, certain corporations cited the FDA in court to ground their refusal to cover emergency contraception for their employees based on their religious freedom. To understand why zygote-centric values had come to constitute the "drug fact" in the first place, we turn to these uses of this mechanistic knowledge for refusals by anti-abortionists.

The proceedings of Burwell v. Hobby Lobby Stores, Inc. exemplify the asymmetry of the social utility of this drug label. After President Barack Obama signed the Patient Protection and Affordable Care Act ("Obamacare") in 2010, the Department of Health and Human Services (HHS) decided that new insurance plans must provide women full coverage of all FDA-approved contraceptives as preventive health care. In response, the craft store chain Hobby Lobby and the Christian bookstore chain Mardel claimed that HHS violated their religious freedom. According to the FDA, services like Plan B may act abortifaciently (at least under zygote-centric definitions). The appeals court acknowledged the "ongoing medical debate" about Plan B based on conflicting amicus briefs, but it decided not to "wade into scientific waters" since all parties agreed that other contraceptives had post-fertilization potential. ${ }^{107}$ At the next legal stage, the Supreme Court relied on the FDA's webpage about Plan B's label, and it ruled in favor of the zygote-centric business owners, allowing them and other closely held, for-profit firms to refuse covering abortifacients for their employees. ${ }^{108}$

The US situation sharply contrasts with France and elsewhere in Europe, where the label no longer reads "may prevent implantation." After attending a 1996 meeting of Sharon Camp's ICEC, André Ulman (a developer of the abortion pill) returned to France to found HRA Pharma. Responding to the rise in unplanned teenage pregnancies, his company introduced NorLevo (equivalent to Plan B) to the French market in April 1999 as a prescription drug and then over-the-counter within a month. The following year, the French legislature made NorLevo free for minors at pharmacies and available through school nurses. ${ }^{109}$ Now HRA Pharma supplies dealers throughout Europe and the globe, including in Japan, South Africa, and Venezuela. ${ }^{110}$

Earlier labeling in NorLevo's patient insert described the mechanism as "unknown [inconnu]" though possibly anti-ovulatory or anti-implantation. ${ }^{111}$ Yet, many women's health advocates had increasingly come to see this hedged association with implantation action as a groundless threat to the emergency 
contraception market outside France, especially in the overwhelmingly Catholic country of Italy. ${ }^{112}$ This suspicion was further solidified by newer negative studies with novel methods, such as artificial endometrial constructs. ${ }^{113}$ Subsequently, the International Federation of Obstetrics and Gynecology issued a joint report with ICEC citing evidence that these drugs "cannot prevent implantation of a fertilized egg," so "language on implantation should not be included in [levonorgestrel-only emergency contraception pills'] product labeling." ${ }^{114}$ Responding to these developments, HRA Pharma filed to change the label in 2013 to clarify the mechanism as only anti-ovulatory and to emphasize the inefficacy of the drug if taken after ovulation. ${ }^{115}$

The social life of this "drug fact" raises important questions: How could the same piece of information that the French manufacturer was removing from its label be the scientific premise of a high-stakes US court case? In addition to divergent value judgments about uncertainty (see $\S 3$ ), what allowed for this contemporaneous discrepancy in the demand and uptake of knowledge across the Atlantic?

Particularly because of the epistemic authority of the FDA, the "drug fact" in the United States had social currency in the Supreme Court, solidifying dominant values and power imbalances through an apparently value-free "drug fact." For one, US medicine is generally fetal-centric, limiting the rights and agency of women (pregnant, nearly pregnant, or possibly pregnant) in deference to the health and interests of their developing fetuses. ${ }^{116}$ Zygote-centrists have substantial institutional power in US health care and health policy, including the growth of Catholic hospitals, the lobbying of the US bishops, and the weaker separation of church and state. ${ }^{117}$ Relatedly, "religious freedom" laws such as the Religious Freedom Restoration Act have protected the expression of religious providers' beliefs over those of their would-be recipients. Furthermore, the US insurance system entangles employers in the health care system because most insured individuals receive coverage from their work rather than the state. ${ }^{118}$ Unlike in France, the US legal and medical cultures legitimate the power of would-be providers to refuse furnishing debatably essential medicines, rather than the rights of women as patients and the priority of their values. These power asymmetries are ultimately rooted in patriarchy, the systematic inequality between cisgender men and "weaker" genders like women, neglecting women's interests and weakening advocacy for their rights. ${ }^{119}$

My answer to the earlier questions reveals how the social utility of a scientific fact depends on its social currency: Power imbalances in US health care and policy intersected differentially to empower zygote-centrists to promote their goal of limiting access to Plan B. These social structures created the epistemic conditions for providers to impose their values on potential users, with zygotecentrists utilizing this "drug fact" as a powerful tool to withhold drugs and refuse coverage. While it is beyond the scope of this paper to discuss this further, these 
"successes" for zygote-centrists came at the undue cost of women's interests as consumers, patients, and persons: the "drug fact" effectively limited their access, compromised their health, and disrespected their values and their right to selfdetermination. ${ }^{120}$

The social value of knowledge is analytically distinct from the constitutive functioning of values, yet pragmatics link the two senses (see $§ 2.4$ ). Zygotecentric goals and strategies swayed knowledge production toward information that was useful and powerful according to their anti-abortionist values. Pragmatic goals also influenced the management of scientific uncertainty and determined the social currency for the consumption of such knowledge. The production of facts in pharmaceutical policy fits into different economies of knowledge with associated political and financial currencies in drug markets, the health care industry, and health law. In precisely the way that the "drug fact" about Plan B's mechanism continues to enable zygote-centrists to control women and their bodies, scientific knowledge is socially value-laden by functioning unevenly in society-benefitting certain interests while undermining others.

\section{The Value of Hedging Your Hypotheses}

I have argued that even hedged hypotheses like Plan B's "drug fact" can be valueladen in two senses, the constitutive and the social. Accordingly, my analysis undermines the plausibility of a strict fact/value division of labor and, thus, the ability of scientists to give policy makers value-free advice. ${ }^{121}$ For instance, according to philosophers like Betz, adopting "plain hypotheses" would require scientists to make ethical judgments by setting standards of evidence according to their valuation of social risks. Here, Betz is agreeing with Douglas, who has shown that decisions about inductive risk are scattered throughout science and, thus, argues that scientists ought to consider the ethical consequences of their methodological choices. ${ }^{122}$ Yet, in contrast with Douglas, Betz contends that scientists ought to avoid making these value judgments and should communicate uncertainty to policy makers by formulating "hedged hypotheses that make the uncertainties explicit." 123 His examples for communicating this practical certainty include showing the range of possible interpretations and using epistemic modalities, such as "it is unlikely/it is possible/it is plausible/etc. that . .."124

Yet Betz's alleged solution to the challenges of values in science is not a value-free one because, as we saw in section 3, even hedged hypotheses can rely on value-laden assumptions about selecting and limiting the body of relevant evidence. ${ }^{125}$ Furthermore, different standards for "may" (or "it is possible that") can be constitutively value-laden, such as how the standards of evidence for rare and remote biological possibility operative in the "drug fact" are based on zygote-centric values. Even just as a "may," the hedging could emphasize the positive possibility — albeit remote—by making the potential more salient, thus 
prompting skeptics to take post-fertilization mechanisms more seriously than they might have otherwise. ${ }^{126}$

Moreover, as we saw in section 4, official association of this drug with implantation, even just the hedging language of "may," was affirmative enough for anti-abortionists in the United States to exert legal power over women and their bodies in pharmacies and through (lack of) insurance coverage. Thus, Betz's hedging strategy can also be socially value-laden: the unequal distribution of power in society enables powerful actors to accomplish their goals with hedged claims, as if the hedging and uncertainty were not there.

Accordingly, this case casts doubt on the value-freedom of Betz's proposal and thus his defense of value-freedom for science advisors. I have concluded that values are inextinguishable from this "drug fact" because of the deep entanglement of fact and value and the uneven social function for anti-abortionists. Note well: I do not take my case study as evidence that values are ineliminable from all drug facts, all regulatory science, or all scientific knowledge. While I am sympathetic to such conclusions, I am not arguing here for the universalizability of this case study and my two-fold account of value-ladenness. Instead, I am making a more specified critique, using an abstract account of value-ladenness and a concrete case of a hedged hypothesis that is clearly and indissolubly value-laden to argue against Betz's claim that hedged hypotheses are value-free.

One might object to my criticism of Betz's defense of the Value-Free Ideal particularly based on my conclusion that this piece of science was ineliminably and inextinguishably value-laden. The root of the problem, one might say instead, was the exceedingly high level of uncertainty in the science about the mechanism during the early 2000s. Since then, uncertainty among scientists has decreased, particularly given the new in vitro and in silico methods for assessing mechanisms, which even convinced some zygote-centrists of Plan B's impotence post-fertilization. ${ }^{127}$ If the uncertainty is in fact decreasing over time along with value-based disagreements, maybe such value-ladenness is only temporary and thus eliminable after all.

In response, I doubt there will be any definitive, decisive resolution over the empirical matter between anti-abortionists and women's health advocates because of how entangled values are in their assessment of "the facts." The debate over the mechanisms of morning-after pills has a 50-year history, which does not appear to be ending anytime soon. ${ }^{128}$ Despite some recent convergence between zygote-centrists and their critics, this shift has been due partly to increased moral concern from zygote-centrists for the rights of rape survivors, resulting in a different standard of evidence based on changed values. ${ }^{129}$ Worryingly, there remains a small, influential minority of scientists and physicians who maintain that Plan B may have a post-fertilization effect, and they have the ear of the powerful Catholic Medical Association and the influential National Catholic Bioethics Center. ${ }^{130} \mathrm{I}$ suspect that these holdouts are those (suggested by Trussell and his colleagues) 
who interpret the drug fact in an untestable and thus unfalsifiable manner-because of their extraordinarily high standards of evidence and "politics of doubt."

Furthermore, even if the uncertainties evaporated with time, this would only reduce the constitutive sense of value-ladenness. Knowledge about the mechanism would still be value-laden in the social sense because it would provide anti-abortionists more leverage to accomplish their political goals than it would afford women's health advocates to increase access to these pills. Even without the uncertainty, reproductive politics remain influential on the assertions made by advisors in regulatory science. Accordingly, defenders of the Value-Free Ideal like Betz need to account for how scientific assertions function socially in valueladen ways.

Distinguishing the constitutive and social senses of value-ladenness allows us to see how and why facts are value-laden, particularly in the realm of public policy involving science advisors. This approach provides a synthetic account of the various, integrated roles that values can play in the constitution of facts in regulatory science. Attending to the social value of science illustrates how the broader economy of knowledge affects the utility and currency of facts, such as enabling providers to impose their views on their patients and limit women's health and agency. As these two senses are interdependent, the epistemic entanglement of science and policy suggests that ethical and political values are inexorable throughout much of regulatory science.

Rather than striving for value freedom, I aim for this critical analysis to inform normative efforts to improve the persistent value-ladenness of policy-relevant science for social justice and the common good. Fallacious beliefs in value-freedom can be pernicious: the perceived value-freedom of the "drug fact" enabled antiabortionists to exploit it for their own ends, imposing their values on women and compromising their health and self-determination. By exposing the zygote-centric constitution of this label and its function for refusing cisgender women drugs, my analysis deflates the insistence of its value-freedom and takes the first step toward a more normative evaluation. ${ }^{131}$

New Mexico Institute of Mining and Technology (New Mexico Tech)

\section{NOTES}

Special thanks to following for their comments and support: Evan Arnet, Josua AponteSerrano, Jim Capshew, Taeyin ChoGlueck, Kevin Elliott, Archie Fields, Justin Garcia, Tom Gieryn, Sandy Gliboff, Kate Grauvogel, Nora Hangel, Bennet Holman, Stephen John, Ashley Graham Kennedy, Ryan Ketchum, Elisabeth Lloyd, Ali Mirza, Sarah Reynolds, and Jutta Schickore. I also thank David Boonin for his helpful editorial comments. This paper is based upon presentations at the 2016 Society for the Philosophy of Science in Practice (SPSP) and the 2016 and 2018 Philosophy of Science Association (PSA). This 
material is based in part on work supported by the National Science Foundation Graduate Research Fellowship Program under Grant No. 1342962. Any opinions, findings, and conclusions or recommendations expressed in this material are those of the author and do not necessarily reflect the views of the National Science Foundation.

1. Burwell v. Hobby Lobby Stores, Inc., 134 S. Ct. 2751, 2763n7 (2014). Figure from FDA, "Label, Insert, and CARE Program."

2. HAS, "NorLevo Renewal of Registration"; FIGO and ICEC, "Statement on Mechanism"; Belluck, "New Birth Control Label."

3. Longino, Science as Social Knowledge, 216; Douglas, Science, Policy, 18.

4. Biddle and Kukla, "Geography of Epistemic Risk"; Brigandt, "Social Values Influence."

5. Elliott, Tapestry of Values.

6. Mitchell, "Prescribed and Proscribed Values"; Bright, "Du Bois' Democratic Defence."

7. See Betz ("In Defence," 212). I thank Kevin Elliott for suggesting this line of critique.

8. See Betz ("Why the Argument," 98; "In Defence," 213).

9. Many philosophical accounts of evidence-based policy actively choose to ignore how ethics and politics interact with scientists' assessments of evidence. See, for example, Cartwright and Hardie (Evidence-Based Policy, 12) and Russo ("Public Health Policy," 145n3). Compare these with Douglas (Science, Policy); Biddle, Kidd, and Lueschner ("Epistemic Corruption"); Holman and Geislar ("Sex Drugs"); and Intemann ("Who Needs Consensus").

10. See Cranor (Regulating Toxic Substances); Elliott (Is a Little Pollution); ShraderFrechette (Risk and Rationality).

11. Particularly one key meeting on December 16, 2003 (FDA, "Nonprescription Drugs").

12. Carpenter, Reputation and Power, 471.

13. While these debates over Plan B focused exclusively on cisgender women, access to contraception also directly affects anyone with a uterus who can get pregnant, including some transmen and non-binary people.

14. Jackson et al., "Advance Supply." For more on this controversy, see Wynn and Trussell ("Social Life"; "Images of American Sexuality").

15. Wood, "Women's Health," 1650.

16. Grimes, "Emergency Contraception: Politics Trumps Science"; Drazen, Greene, and Wood, "FDA, Politics, and Plan B"; Stanford, Hager, Crockett, "FDA, Politics, and Plan B."

17. Jasanoff, Fifth Branch; Carpenter, Reputation and Power.

18. GAO, "Food and Drug Administration."

19. Prescott, Morning After. 
20. FDA, "Label, Insert, and CARE Program"; emphasis added.

21. Duden, Disembodying Women; Lupton, "'Precious Cargo";; Rothman, Recreating Motherhood; Annas, "Pregnant Women"; Macklin, "Maternal-Fetal Conflict"; Purdy, "Are Pregnant Women."

22. Armstrong, Conceiving Risk.

23. See note 13 on contraception access for transgender men and non-binary people.

24. Williams, Defenders of the Unborn.

25. USCCB, Ethical and Religious Directives; see also CFFC ("Facts about Catholic"); Miller (Good Catholics).

26. For instance, zygote-centric advisors Joseph Stanford and David Hager were professors at University of Utah and University of Kentucky, respectively, while their critics Linda Giudice and James Trussell were professors at Stanford and Princeton. During the public forum, zygote-centric concerns were echoed by leaders of Human Life International and American Life League. See FDA ("Nonprescription Drugs").

27. Miller, Good Catholics.

28. For instance, Stanford is a pro-life Mormon (see his "Fertility Respect"). For more history of the Pro-Life Movement, see Williams (Defenders of the Unborn).

29. FDA, "Nonprescription Drugs," 240.

30. Prescott, Morning After; ChoGlueck, "Broadening the Scope."

31. See note 26. Regarding the drug sponsor, Carole Ben-Maimon from Barr Pharmaceuticals also criticized zygote-centrists during the hearings (FDA, "Nonprescription Drugs," 267-68).

32. Prescott, Morning After.

33. Wilks, "Impact of the Pill"; Larimore, Stanford, and Kahlenborn, "Does Pregnancy Begin."

34. Wilks, "Impact of the Pill," 19.

35. Anderson, Mosby's Medical; Wilks, "Impact of the Pill," 15; Larimore, Stanford, and Kahlenborn, "Does Pregnancy Begin," 690.

36. Glasier, "Emergency Postcoital Contraception," 1063; Trussell et al., "Role of Emergency Contraception."

37. Gold, "Implications of Defining."

38. Hughes, Obstetric-Gynecologic Terminology; for the "Common Rule" on Protection of Human Subjects, see DHHS ["Protection of Human Subjects," 45 C.F.R. § 46.202(f)].

39. Wilks, "Impact of the Pill," 20; see also Larimore and Stanford ("Postfertilization Effects"); FDA (“Nonprescription Drugs," 213).

40. Ashley and O'Rourke, Health Care Ethics.

41. USCCB, Ethical and Religious Directives, 21; emphasis added.

42. Grimes, "Emergency Contraception and Fire Extinguishers"; Coeytaux and Pillsbury, "Bringing Emergency Contraception." 
43. Trussell et al., "Role of Emergency Contraception"; ACOG, "Emergency Oral Contraception."

44. Grimes, Raymond, and Jones, "Emergency Contraception Over-the-Counter"; Trussell et al., "Role of Emergency Contraception"; for more, see Prescott (Morning After).

45. Prescott, Morning After, 106.

46. Kahlenborn, Stanford, and Larimore, "Postfertilization Effect"; Wilks, "Impact of the Pill."

47. Miller, Good Catholics; Larimore and Stanford, "Postfertilization Effects," 133; Wilks, "Why This Pharmacy."

48. USCCB, Ethical and Religious Directives, dir. 36.

49. Cataldo and Moraczewski, Catholic Health Care Ethics, chap. 11.

50. Smugar, Spina, and Merz, "Informed Consent."

51. Bucar, Caution.

52. Pennsylvania Catholic Conference, "Guidelines for Catholic Hospitals."

53. See, for example, Ashley and O'Rourke (Health Care Ethics); Pope John Paul II ("Teachers of Moral Truth"; "Building a Culture").

54. Trussell et al., "Call 1-888-NOT-2-LATE."

55. Ellertson et al., "Should Emergency Contraceptive Pills," 229; Coeytaux and Pillsbury, "Bringing Emergency Contraception"; Grimes, Raymond, and Jones, "Emergency Contraception Over-the-Counter."

56. Murphy, Seizing the Means.

57. Prescott, Morning After, 103-04.

58. For more on asserting versus accepting a hypothesis, see Franco ("Assertion, Nonepistemic Values").

59. See, for example, Jean and Lu (“Evolution as a Fact?"); Oreskes (“My Facts Are Better").

60. My conception of facts is similar to Ludwig Fleck's constructivist account (Genesis and Development).

61. For more on the relation between the rational and social aspects of science, see Longino (Fate of Knowledge).

62. For related synthetic work, see Biddle and Kukla ("Geography of Epistemic Risk"); ChoGlueck ("Error Is in the Gap"); Elliott (Tapestry of Values).

63. Longino, Science as Social Knowledge; "Values, Heuristics."

64. Douglas, Science, Policy.

65. Elliott, Is a Little Pollution.

66. Elliott, Is a Little Pollution.

67. Wilks, "Impact of the Pill"; Kahlenborn, Stanford, and Larimore, "Postfertilization Effect."

(๑) Copyright 2021 by the Board of Trustees of the University of Illinois. No part of this article may be reproduced, photocopied, posted online, or distributed through any means without the permission of the University of Illinois Press. 
68. Chang, "Physiological Mechanisms"; Grou and Rodrigues, "Morning-after Pill."

69. Díaz et al., "Acceptability of Emergency Contraception."

70. FDA, "Nonprescription Drugs," 270-71.

71. FDA, "Nonprescription Drugs," 31, 266-69, 393, 342.

72. FDA, "Nonprescription Drugs," 199, 269-71.

73. Douglas, Science, Policy.

74. As an anonymous reviewer pointed out, one might see these parties as operating under the precautionary principle. I will not discuss its application here, however, since this principle is mired in confusion over its interpretation. For a critical revisionary account, see Steel (Philosophy and the Precautionary Principle).

75. Wilks, "Impact of the Pill," 20.

76. I thank Kevin Elliott for helping me elaborate this semantic nuance about possibility.

77. Kahlenborn, Stanford, and Larimore, "Postfertilization Effect," 468; emphasis added.

78. Larimore and Stanford, "Postfertilization Effects," 130; Kahlenborn, Stanford, and Larimore, "Postfertilization Effect," 468.

79. Croxatto et al., "Mechanism of Action," 118.

80. Davidoff and Trussell, "Plan B and the Politics."

81. Davidoff and Trussell, "Plan B and the Politics," 1777.

82. Douglas, Science, Policy; Elliott, Is a Little Pollution.

83. FDA, "Nonprescription Drugs," 267-68.

84. FDA, "Nonprescription Drugs," 270.

85. FDA, "Nonprescription Drugs," 271.

86. von Hertzen et al., "Low Dose Mifepristone," table 4, 1807.

87. von Hertzen et al., "Low Dose Mifepristone," 1809; emphasis added.

88. FDA, "Nonprescription Drugs," 272.

89. Longino, Science as Social Knowledge; "Values, Heuristics."

90. Larimore and Stanford, "Postfertilization Effects," 129.

91. Kahlenborn, Stanford, and Larimore, "Postfertilization Effect," 467.

92. Population Council, "Emergency Contraception's Mode."

93. FDA, "Nonprescription Drugs," 292.

94. FDA, "Nonprescription Drugs," 319, 398ff.; "Label, Insert, and CARE Program"; "Birth Control: Medicines."

95. FDA, "Nonprescription Drugs," 326-27; emphasis added.

96. Davidoff and Trussell, "Plan B and the Politics," 1777. 
97. Elsewhere, I have argued that, in the realm of regulatory science, mechanistic knowledge about the morning-after pill can be understood as a political instrument for/ against women's access and agency. See ChoGlueck ("Broadening the Scope").

98. Kourany, Philosophy of Science.

99. Howlett and Morgan, How Well Do Facts.

100. Davidson et al., "Religion and Conscientious Objection"; ACOG, "Limits of Conscientious Refusal."

101. I thank Tom Gieryn and Kevin Elliott for pressing me to discuss the potential, limited benefits that a hedged label would have for women's health.

102. Gold, "Implications of Defining"; contrast with Davidoff and Trussell ("Plan B and the Politics").

103. Daniels, Jones, and Abma, "Use of Emergency Contraception."

104. Crary, "Sales Soar."

105. See Teva Pharmaceutical Industries ("Teva Reports").

106. Berenson, "Next-Day Pill"; Stein, "Plan B Use Surges."

107. Hobby Lobby Stores v. Sebelius, 723 F.3d 1114, 1123n3 (10th Cir. 2013).

108. See note 1. For webpage, see FDA ("Birth Control: Medicines").

109. Moreau and Gainer, "France: A Pioneer."

110. See ICEC ("EC Status and Availability").

111. HAS, "NorLevo Renewal of Registration," 9.

112. Belluck, "Abortion Qualms."

113. Lalitkumar et al., "Mifepristone, but Not Levonorgestrel."

114. FIGO and ICEC, "Statement on Mechanism."

115. Belluck, "New Birth Control Label"; HAS, "NorLevo Renewal of Registration," 9.

116. See note 21 on fetal-centrism.

117. Miller, Good Catholics; CFFC, "Facts about Catholic Health Care."

118. Barnett and Berchick, "Health Insurance Coverage."

119. See hooks (Will to Change); Manne (Down Girl).

120. I provide evidence for this claim in my forthcoming paper. See ChoGlueck ("Imposing Values").

121. For related defenses of the Value-Free Ideal in science policy, see Mitchell ("Prescribed and Proscribed Values"); Bright ("Du Bois' Democratic Defence," 2240).

122. Douglas, Science, Policy.

123. Betz, "In Defence," 212.

124. Betz, "In Defence," 213. See also Betz ("Why the Argument"). 
125. See also John ("Example of the IPCC").

126. I thank Steven John for this insight.

127. For a review on the mechanism near the time of the Supreme Court case, see Gemzell-Danielsson, Berger, and Lalitkumar ("Emergency Contraception"); for zygotecentrists who accept the inability of Plan B to act post-fertilization, see, for example, Austriaco ("Is Plan B an Abortifacient?"); Reznik ("'Plan B'”); Talone ("Time of Special Need").

128. ChoGlueck, "Broadening the Scope."

129. See Holbrook (“Sexual Violence”); Talone ("Time of Special Need”).

130. Kahlenborn, Peck, and Severs, "Mechanism of Action"; Raviele et al., "Statement on Emergency Contraception."

131. In a follow-up paper, I use the framework of epistemic oppression for this next step. See ChoGlueck ("Imposing Values").

\section{REFERENCES}

American College of Obstetricians and Gynecologists [ACOG]. "Emergency Oral Contraception." International Journal of Gynecology and Obstetrics 56, no. 3 (1997): 290-97.

- "The Limits of Conscientious Refusal in Reproductive Medicine: ACOG Committee Opinion No. 385." Obstetrics \& Gynecology 110, no. 5 (2007; reaffirmed 2016): 1203-08.

Anderson, Douglas M., ed. Mosby's Medical, Nursing \& Allied Health Dictionary. 6th ed. St. Louis, MO: Mosby, 2002.

Annas, George J. "Pregnant Women as Fetal Containers." Hastings Center Report 16, no. 6 (1986): 13-14.

Armstrong, Elizabeth M. Conceiving Risk, Bearing Responsibility: Fetal Alcohol Syndrome \& the Diagnosis of Moral Disorder. Baltimore, MA: Johns Hopkins University Press, 2003.

Ashley, Benedict M., and Kevin D. O'Rourke, eds. Health Care Ethics: A Theological Analysis. 4th ed. Washington, DC: Georgetown University Press, 1997.

Austriaco, Nicanor Pier Giorgio. "Is Plan B an Abortifacient?" National Catholic Bioethics Quarterly 7, no. 4 (2007): 703-07.

Barnett, Jessica C., and Edward R. Berchick. "Health Insurance Coverage in the United States: 2016." Current Population Reports, No. P60-260, US Census Bureau. Washington, DC: US Government Printing Office, 2017. https://www.census.gov/library /publications/2017/demo/p60-260.html.

Belluck, Pam. "Abortion Qualms on Morning-After Pill May Be Unfounded.” New York Times, June 5, 2012. http://www.nytimes.com/2012/06/06/health/research/morning -after-pills-dont-block-implantation-science-suggests.html.

_ "New Birth Control Label Counters Lawsuit Claim." New York Times, November 26, 2013. http://www.nytimes.com/2013/11/27/us/shift-on-birth-control-pill-may -affect-court-cases.html. 
Berenson, Alex. "Next-Day Pill No Pot of Gold for Its Maker." New York Times, August 25, 2006. https://www.nytimes.com/2006/08/25/business/25barr.html.

Betz, Gregor. "In Defence of the Value Free Ideal." European Journal for Philosophy of Science 3, no. 2 (2013): 207-20.

—. "Why the Argument from Inductive Risk Doesn't Justify Incorporating NonEpistemic Values in Scientific Reasoning." In Current Controversies in Values and Science, edited by Kevin C. Elliott and Daniel Steel, 94-110. New York: Routledge, 2017.

Biddle, Justin B., Ian James Kidd, and Anna Leuschner. "Epistemic Corruption and Manufactured Doubt: The Case of Climate Science." Public Affairs Quarterly 31, no. 3 (2017): 165-87.

Biddle, Justin B., and Rebecca (Quill) Kukla. “The Geography of Epistemic Risk.” In Exploring Inductive Risk, edited by Kevin C. Elliott and Ted Richards, 215-37. Oxford, UK: Oxford University Press, 2017.

Brigandt, Ingo. "Social Values Influence the Adequacy Conditions of Scientific Theories: Beyond Inductive Risk." Canadian Journal of Philosophy 45, no. 3 (2015): 326-56.

Bright, Liam Kofi. "Du Bois' Democratic Defence of the Value Free Ideal." Synthese 195, no. 5 (2018): 2227-45.

Bucar, Elizabeth. Caution: Catholic Health Restrictions May Be Hazardous to Your Health. Washington, DC: Catholics for a Free Choice, 1999. https://www.catholicsforchoice .org/wp-content/uploads/2014/01/1998cautioncatholichealthrestrictions.pdf.

Carpenter, Daniel. Reputation and Power: Organizational Image and Pharmaceutical Regulation at the FDA. Princeton, NJ: Princeton University Press, 2010.

Cartwright, Nancy, and Jeremy Hardie. Evidence-Based Policy: A Practical Guide to Doing It Better. Oxford, UK: Oxford University Press, 2012.

Cataldo, Peter J., and Albert S. Moraczewski, eds. Catholic Health Care Ethics: A Manual for Ethics Committees. Boston, MA: National Catholic Bioethics Center, 2001.

Catholics for a Free Choice [CFFC]. "The Facts about Catholic Health Care in the United States." 2005. http://www.catholicsforchoice.org/wp-content/uploads/2014/01/2005 factsaboutcatholichealthcare_000.pdf.

Chang, Min Chueh. "Physiological Mechanisms Responsible for the Effectiveness of Oral Contraception." In Proceedings of the Eighth International Conference of the International Planned Parenthood Federation, Santiago, Chile, edited by R. K. B. Hankinson, R. L. Kleinman, and Peter Eckstein, 386-92. London: International Planned Parenthood Federation, 1967.

ChoGlueck, Christopher. "Broadening the Scope of Our Understanding of Mechanisms: Lessons from the History of the Morning-After Pill.” Synthese (2019). doi.org/10.1007 /s11229-019-02201-0.

- "The Error Is in the Gap: Synthesizing Accounts for Societal Values in Science." Philosophy of Science 85, no. 4 (2018): 704-25.

—. "Imposing Values and Enforcing Gender through Knowledge: Epistemic Oppression with the Morning-after Pill's Drug Label." Hypatia, forthcoming.

Coeytaux, Francine, and Barbara Pillsbury. "Bringing Emergency Contraception to American Women: The History and Remaining Challenges." Women's Health Issues 11, no. 2 (2001): 80-86.

Cranor, Carl F. Regulating Toxic Substances: A Philosophy of Science and the Law. New York: Oxford University Press, 1993. 
Crary, David. “Sales Soar for Morning-After Pill.” Washington Post, August 22, 2007. http:// www.washingtonpost.com/wp-dyn/content/article/2007/08/22/AR2007082201593 .html.

Croxatto, Horacio B., Luigi Devoto, Marta Durand, Enrique Ezcurra, Fernando Larrea, Carlos Nagle, Maria Elena Ortiz, et al. "Mechanism of Action of Hormonal Preparations Used for Emergency Contraception: A Review of the Literature." Contraception 63, no. 3 (2001): 111-21.

Daniels, Kimberly, Jo Jones, and Joyce C. Abma. "Use of Emergency Contraception among Women Aged 15-44, United States, 2006-2010.” NCHS data brief, No. 112. Hyattsville, MD: National Center for Health Statistics, 2013. https://www.cdc.gov /nchs/data/databriefs/db112.pdf.

Davidoff, Frank, and James Trussell. "Plan B and the Politics of Doubt." Journal of the American Medical Association 296, no. 14 (2006): 1775-78.

Davidson, Laura A., Clare T. Pettis, Amber J. Joiner, Daniel M. Cook, and Craig M. Klugman. "Religion and Conscientious Objection: A Survey of Pharmacists' Willingness to Dispense Medications." Social Science \& Medicine 71, no. 1 (2010): 161-65.

Department of Health \& Human Services [DHHS]. "Protection of Human Subjects," 45 Code of Federal Regulations, 2009. https://www.hhs.gov/ohrp/sites/default/files/ohrp /humansubjects/regbook2013.pdf.pdf.

Díaz, Soledad, Ellen Hardy, Gloria Alvarado, and Enrique Ezcurra. "Acceptability of Emergency Contraception in Brazil, Chile, and Mexico. 2: Facilitating Factors versus Obstacles." Cadernos de Saúde Pública 19, no. 6 (2003): 1729-37.

Douglas, Heather. Science, Policy, and the Value-Free Ideal. Pittsburgh, PA: University of Pittsburgh Press, 2009.

Drazen, Jeffrey M., Michael F. Greene, and A. J. Wood. "The FDA, Politics, and Plan B." New England Journal of Medicine 350, no. 15 (2004): 1561-62.

Duden, Barbara. Disembodying Women: Perspectives on Pregnancy and the Unborn. Translated by Lee Hoinacki. Cambridge, MA: Harvard University Press, 1993.

Ellertson, Charlotte, James Trussell, Felicia Stewart, and B. Winikoff. "Should Emergency Contraceptive Pills Be Available without Prescription?" Journal of the American Medical Women's Association 53, no. 5, supp. 2 (1998): 226-29, 232.

Elliott, Kevin. Is a Little Pollution Good for You? Incorporating Societal Values in Environmental Research. New York: Oxford University Press, 2011.

- A Tapestry of Values: An Introduction to Values in Science. New York: Oxford University Press, 2017.

Federation, International, of Gynecology \& Obstetrics [FIGO] and International Consortium for Emergency Contraception [ICEC]. "Statement on Mechanism of Action: How Do Levonorgestrel-Only Emergency Contraceptive Pills (LNGECPs) Prevent Pregnancy?" Family Care International, October 2008. https://www.figo.org/mechanism-action -emergency-contraception.

Fleck, Ludwig. Genesis and Development of a Scientific Fact. Translated by Frederick Bradley and Thaddeus J. Trenn. Chicago: University of Chicago Press, 1979.

Food and Drug Administration [FDA]. "Birth Control: Medicines to Help You." US Supreme Court Docket No. 13-354, Sebelius v. Hobby Lobby Stores, Inc. 2013. https:// www.supremecourt.gov/opinions/URLs_Cited/OT2013/13-354/13-354-2.pdf.

_. "Label, Insert, and CARE Program Proposal for Plan B.” Drugs@ FDA database, 2006. http://www.accessdata.fda.gov/drugsatfda_docs/label/2006/021045s011lb 1.pdf. 
"Nonprescription Drugs Advisory Committee (NDAC) in Joint Session with the Advisory Committee for Reproductive Health Drugs (ACRHD). Meeting Transcript." Center for Drug Evaluation and Research, December 16, 2003.

Franco, Paul L. "Assertion, Nonepistemic Values and Scientific Practice." Philosophy of Science 84 (2017): 160-80.

Gemzell-Danielsson, Kristin, Cecilia Berger, and P. G. L. Lalitkumar. "Emergency Contraception-Mechanisms of Action." Contraception 87, no. 3 (2013): 300-08.

Glasier, Anna. "Emergency Postcoital Contraception." New England Journal of Medicine 337, no. 15 (1997): 1058-64.

Gold, Rachel Benson. "The Implications of Defining When a Woman Is Pregnant." Guttmacher Report on Public Policy 8, no. 2 (2005): 7-10.

Government Accountability Office [GAO]. "Food and Drug Administration: Decision Process to Deny Initial Application for Over-the-Counter Marketing of the Emergency Contraceptive Drug Plan B Was Unusual." Report to Congressional Requesters, GAO06-109. November 2005. http://www.gao.gov/products/GAO-06-109.

Grimes, David A. "Emergency Contraception and Fire Extinguishers: A Prevention Paradox." American Journal of Obstetrics and Gynecology 187, no. 6 (2002): 1536-38.

- "Emergency Contraception: Politics Trumps Science at the U.S. Food and Drug Administration." Obstetrics \& Gynecology 104, no. 2 (2004): 220-21.

Grimes, David A., Elizabeth G. Raymond, and Bonnie Scott Jones. "Emergency Contraception Over-the-Counter: The Medical and Legal Imperatives." Obstetrics and Gynecology 98, no. 1 (2001): 151-55.

Grou, Fabienne, and Isabel Rodrigues. "The Morning-after Pill-How Long After?" American Journal of Obstetrics and Gynecology 171, no. 6 (1994): 1529-34.

Haute Autorite de Sante [HAS]. "NorLevo Renewal of Registration [Renouvellement de l'inscription], June 3, 2015." Commission de la Transparence. 2015. https://www .has-sante.fr/portail/upload/docs/evamed/CT-13654_NORLEVO_PIS_RI_Avis1_ CT13654.pdf.

Holbrook, Debra S. "Sexual Violence: A Medical Center Responds." Health Progress 91, no. 1 (2010): 56-58.

Holman, Bennett, and Sally Geislar. "Sex Drugs and Corporate Ventriloquism: How to Evaluate Science Policies Intended to Manage Industry-Funded Bias." Philosophy of Science 85, no. 5 (2018): 869-81.

hooks, bell. The Will to Change: Men, Masculinity, and Love. New York: Atria Books, 2004.

Howlett, Peter, and Mary S. Morgan, eds. How Well Do Facts Travel? The Dissemination of Reliable Knowledge. Cambridge, UK: Cambridge University Press, 2010.

Hughes, Edward C., ed. Obstetric-Gynecologic Terminology: With Section on Neonatology and Glossary of Congenital Anomalies. Philadelphia, PA: Davis, 1972.

Intemann, Kristen. "Who Needs Consensus Anyway? Addressing Manufactured Doubt and Increasing Public Trust in Climate Science." Public Affairs Quarterly 31, no. 3 (2017): 189-208.

International Consortium for Emergency Contraception [ICEC]. "EC Status and Availability: NorLevo $0.75 \mathrm{Mg}$." Last updated 2021. http://www.cecinfo.org/country-by -country-information/status-availability-database/pills/norlevo-0-75-mg/ (accessed October 14, 2020).

Jackson, Rebecca A., Eleanor B. Schwarz, Lori Freedman, and Philip Darney. "Advance Supply of Emergency Contraception: Effect on Use and Usual Contraception-A Randomized Trial." Obstetrics and Gynecology 102, no. 1 (2003): 8-16. 
Jasanoff, Sheila. The Fifth Branch: Science Advisers as Policymakers. Cambridge, MA: Harvard University Press, 1990.

Jean, Jason, and Yixi Lu. "Evolution as a Fact? A Discourse Analysis." Social Studies of Science 48, no. 4 (2018): 615-32.

John, Stephen. "The Example of the IPCC Does Not Vindicate the Value Free Ideal: A Reply to Gregor Betz." European Journal for Philosophy of Science 5, no. 1 (2015): 1-13.

Kahlenborn, Chris, Rebecca Peck, and Walter B. Severs. "Mechanism of Action of Levonorgestrel Emergency Contraception.” Linacre Quarterly 82, no. 1 (2015): 18-33.

Kahlenborn, Chris, Joseph B. Stanford, and Walter L. Larimore. "Postfertilization Effect of Hormonal Emergency Contraception." Annals of Pharmacotherapy 36, no. 3 (2002): 465-70.

Kourany, Janet A. Philosophy of Science after Feminism. New York: Oxford University Press, 2010.

Lalitkumar, P. G. L., Sujata Lalitkumar, Chanxia Meng, Anneli Stavreus-Evers, Fredwell Hambiliki, Ursula Bentin-Ley, and Kristina Gemzell-Danielsson. "Mifepristone, but Not Levonorgestrel, Inhibits Human Blastocyst Attachment to an in Vitro Endometrial Three-Dimensional Cell Culture Model." Human Reproduction 22, no. 11 (2007): 3031-37.

Larimore, Walter L., and Joseph B. Stanford. "Postfertilization Effects of Oral Contraceptives and Their Relationship to Informed Consent." Archives of Family Medicine 9, no. 2 (2000): 126-33.

Larimore, Walter L., Joseph B. Stanford, and Chris Kahlenborn. "Does Pregnancy Begin at Fertilization?" Family Medicine 36, no. 10 (2004): 690-91.

Longino, Helen E. The Fate of Knowledge. Princeton, NJ: Princeton University Press, 2002.

- Science as Social Knowledge. Princeton, NJ: Princeton University Press, 1990. . "Values, Heuristics, and the Politics of Knowledge." In The Challenge of the Social and the Pressure of Practice: Science and Values Revisited, edited by Martin Carrier, Don Howard, and Janet A. Kourany, 68-86. Pittsburgh, PA: University of Pittsburgh Press, 2008.

Lupton, Deborah. “'Precious Cargo': Foetal Subjects, Risk, and Reproductive Citizenship." Critical Public Health 22, no. 3 (2012): 329-40.

Macklin, Ruth. "Maternal-Fetal Conflict: An Ethical Analysis." Women's Health Issues 1, no. 1 (1990): 28-30.

Manne, Kate. Down Girl: The Logic of Misogyny. New York: Oxford University Press, 2018.

Miller, Patricia. Good Catholics: The Battle over Abortion in the Catholic Church. Berkeley: University of California Press, 2015.

Mitchell, Sandra D. "The Prescribed and Proscribed Values in Science Policy." In Science, Values, and Objectivity, edited by Peter Machamer and Gereon Wolters, 245-55. Pittsburgh: University of Pittsburgh Press, 2004.

Moreau, Caroline, and Erin Gainer. "France: A Pioneer in the Switch to Nonprescription Status." In Emergency Contraception: The Story of a Global Reproductive Health Technology, edited by Angel M. Foster and Lisa L. Wynn, 139-51. New York: Palgrave Macmillan, 2012.

Murphy, Michelle. Seizing the Means of Reproduction: Entanglements of Feminism, Health, and Technoscience. Durham, NC: Duke University Press, 2012.

Oreskes, Naomi. "My Facts Are Better Than Your Facts: Spreading Good News about Global Warming." In How Well Do Facts Travel?, edited by Peter Howlett and Mary S. Morgan, 136-66. Cambridge, UK: Cambridge University Press, 2011. 
Pennsylvania Catholic Conference. "Guidelines for Catholic Hospitals Treating Victims of Sexual Assault." Origins 22, no. 47 (1993): 810.

Pope John Paul II. "Building a Culture of Life.” Origins 28, no. 18 (1998): 314-16.

_. "Teachers of Moral Truth." Origins 28, no. 16 (1998): 282-84.

Population Council. "Emergency Contraception's Mode of Action Clarified." Population Briefs 11, no. 2 (2005): 3.

Prescott, Heather Munro. The Morning After: A History of Emergency Contraception in the United States. New Brunswick, NJ: Rutgers University Press, 2011.

Purdy, Laura M. “Are Pregnant Women Fetal Containers?” Bioethics 4, no. 4 (1990): 273-91.

Raviele, Kathleen, Chris Kahlenborn, Rebecca Peck, Les Ruppersberger, Patrick Yeung, Jr., Joseph Tham, and Matthew J. Gutowski. "Statement on Emergency Contraception in Cases of Rape." In Catholic Health Care Ethics: A Manual for Practitioners. 3rd ed., edited by Edward J. Furton. Philadelphia: National Catholic Bioethics Center, 2020.

Reznik, Sandra E. “'Plan B': How It Works-Science Shows It Is Not an Abortifacient.” Health Progress 91, no. 1 (2010): 59-61.

Rothman, Barbara Katz. Recreating Motherhood: Ideology and Technology in a Patriarchal Society. New York: Norton, 1989.

Russo, Federica. "Public Health Policy, Evidence, and Causation: Lessons from the Studies on Obesity." Medicine, Health Care and Philosophy 15, no. 2 (2012): 141-51.

Shrader-Frechette, Kristin. Risk and Rationality: Philosophical Foundations for Populist Reforms. Berkeley: University of California Press, 1991.

Smugar, Steven S., Bernadette J. Spina, and Jon F. Merz. "Informed Consent for Emergency Contraception: Variability in Hospital Care of Rape Victims." American Journal of Public Health 90, no. 9 (2000): 1372-76.

Stanford, Joseph B. "Fertility Respect." SquareTwo 4, no. 1 (2011). http://squaretwo.org /Sq2ArticleStanfordNFP.html.

Stanford, Joseph B., W. David Hager, and Susan A. Crockett. "The FDA, Politics, and Plan B: To the Editor." New England Journal of Medicine 350, no. 23 (2004): 2413-14.

Steel, Daniel. Philosophy and the Precautionary Principle: Science, Evidence, and Environmental Policy. Cambridge, UK: Cambridge University Press, 2015.

Stein, Rob. "Plan B Use Surges, and So Does Controversy," Washington Post, July 13, 2007. http://www.washingtonpost.com/wp-dyn/content/article/2007/07/12 /AR2007071202146.html.

Talone, Patricia. “A Time of Special Need.” Health Progress 91, no. 1 (2010): 54-55.

Teva Pharmaceutical Industries. "Teva Reports First Quarter 2009 Results: Strong NonGAAP Earnings; Significant Progress with Barr Integration.” May 5, 2009. https:// ir.tevapharm.com/news-and-events/press-releases/press-release-details/2009/Teva -reports-First-Quarter-2009-Results/default.aspx (accessed October 19, 2020).

Trussell, James, Jessica Bull, Jacqueline Koenig, Marie Bass, Amy Allina, and Vanessa Northington Gamble. "Call 1-888-N0T-2-LATE: Promoting Emergency Contraception in the United States." Journal of the American Medical Women's Association 53 (1998): 247-50.

Trussell, James, Charlotte Ellertson, Felicia Stewart, Elizabeth G Raymond, and Tara Shochet. "The Role of Emergency Contraception." American Journal of Obstetrics and Gynecology 190, no. 4, (2004): S30-S38.

United States Conference of Catholic Bishops [USCCB]. Ethical and Religious Directives for Catholic Health Care Services. 4th ed. Washington, DC: USCCB, 2001. 
von Hertzen, Helena, Gilda Piaggio, Alexandre Peregoudov, Juhong Ding, Junling Chen, Si Song, György Bártfai, et al. "Low Dose Mifepristone and Two Regimens of Levonorgestrel for Emergency Contraception: A WHO Multicentre Randomised Trial." The Lancet 360, no. 9348 (2002): 1803-10.

Wilks, John. "The Impact of the Pill on Implantation Factors: New Research Findings." Ethics and Medicine 16, no. 1 (2000): 15-22.

—. "Why This Pharmacy Does Not Sell the 'Morning-After' Pill." LifeIssues.net, February 18, 2004. http://www.lifeissues.net/writers/wilks/wilks_05map.html.

Williams, Daniel K. Defenders of the Unborn: The Pro-Life Movement before Roe v. Wade. New York: Oxford University Press, 2016.

Wood, Susan F. "Women's Health and the FDA.” New England Journal of Medicine 353, no. 16 (2005): 1650-51.

Wynn, Lisa L., and James Trussell. "Images of American Sexuality in Debates over Nonprescription Access to Emergency Contraceptive Pills." Obstetrics and Gynecology 108, no. 5 (2006): 1272-76.

. "The Social Life of Emergency Contraception in the United States: Disciplining Pharmaceutical Use, Disciplining Sexuality, and Constructing Zygotic Bodies." Medical Anthropology Quarterly 20, no. 3 (2006): 297-320. 